Gene, $104(1991) 99-102$

(C) 1991 Elsevier Science Publishers B.V. All rights reserved 0378-1119/91/\$03.50

GENE 05069

\title{
New shuttle vectors for direct cloning in Saccharomyces cerevisiae
}

(Recombinant DNA; gene cloning; plasmid; yeast)

\section{Philippe Silar and Dennis J. Thiele}

Department of Biological Chemistry, The University of Michigan Medical School, Ann Arbor, MI 48109 (U.S.A.)

Received by G.P. Livi: 6 March 1991

Revised/Accepted: 15 April/6 May 199I

Received at publishers: 23 May 1991

\section{SUMMARY}

We have constructed new shuttle vectors to facilitate the screening of recombinant plasmids after direct transformation of yeast cells. The vectors are pBluescript-based shuttle vectors in which the lac $Z$ marker has been replaced by an analogous system based on the Saccharomyces cerevisiae URA3 gene. DNA fragments are inserted in a polylinker located after the beginning of the $U R A 3$ coding sequence. Transformants are selected either by Trp or Leu prototrophy. Plasmids bearing an insert are selected by growth on 5-fluoro-orotic acid (5-FOA), a uracil analog toxic to cells containing a functional URA3 ${ }^{+}$ gene (thus, this method requires the recipient strain to be $u r a 3^{-}$); only cells containing a plasmid with an insert that disrupts the functional continuity of the $U R A 3$ gene can grow on medium containing 5-FOA. Using these plasmids, we were able to directly reclone the $A C E 1$ gene from genomic DNA by directly transforming a strain deleted for $A C E 1$. These vectors can be used for a variety of purposes including rapid cloning of genes by complementation or expression of fusion genes driven from the $U R A 3$ promoter.

\section{INTRODUCTION}

Complementation of mutations which exhibit specific phenotypes is a common method used to clone genes in the yeast $S$. cerevisiae. Unlike recessive alleles, however, it is difficult to clone genes containing dominant mutations by

Correspondence to: Dr. P. Silar, Laboratoire d'Embryologie Moléculaire, Bât. 445, U.P.S., 91405 Orsay Cedex (France)

Tel. (1)69417225; Fax (1)69853538.

Abbreviations: $A C E 1$, gene encoding the activator of $C U P 1$ expression; $A R S$, autonomously replicating sequence; bp, base pair(s); $C E N$, centromeric sequence; 5-FOA, 5-fluoro-orotic acid; kb, kilobase(s) or $1000 \mathrm{bp} ; L E U 2$, gene encoding $\beta$-isopropylamate dehydrogenase; $\mathrm{nt}$, nucleotide(s); ori, origin of DNA replication; PolIk, Klenow (large) fragment of E. coli DNA polymerase I; S., Saccharomyces; SC, synthetic complete medium; ss, single strand(ed); TRPl, gene encoding $N$ - $\left(5^{\prime}\right.$ phosphate)-anthranilate isomerase; $2 \mu, 2-\mu \mathrm{m}$ plasmid of $S$.cerevisiae; $U R A 3$, gene encoding orotidine-5' -phosphate decarboxylase. this method. This usually requires the construction of a genomic DNA bank in Escherichia coli derived from the mutant strain, subsequent transformation of a wild-type yeast strain and then screening for the appearance of the mutant phenotype. Construction of such genomic banks is a time-consuming procedure primarily due to the intermediate step in $E$. coli. The potential toxicity of some yeast genes in $E$. coli could also present difficulties in cloning specific yeast sequences. Direct transformation of yeast cells with a ligation mixture containing a vector and genomic DNA from the mutant strain could be a rapid and convenient way of cloning. However, the vector must contain a marker to select for recombinant plasmids in yeast to monitor the insertion efficiency of DNA fragments into the vector.

The URA3 gene (Rose et al., 1984) is ideal for the development of such a selection system. In the presence of 5-FOA, URA3' cells perish, whereas $u r a 3^{-}$cells remain viable (Boeke et al., 1984). Disruption of the $U R A 3$ gene by 
insertion of a DNA fragment at the beginning of the coding sequence should, in most cases, inactivate the gene, allowing growth on 5-FOA and providing an easy selection for recombinant plasmids. This can be performed only by transforming yeast strains that have a nonfunctional $U R A 3$ gene ( $u r a 3^{-}$strains). This scheme is similar to the disruption of the $\alpha$-peptide of $\beta$-galactosidase used in the pUC-derived vectors (Yanisch-Perron et al., 1985), however, it provides the additional advantage of a positive selection for recombinant plasmids. We thus have introduced a pBluescript polylinker (Stratagene, La Jolla, CA) at the beginning of the $U R A 3$ coding sequence and replaced the lac $Z$ cassette with this modified $U R A 3$ gene in some of the shuttle vectors of the pRS scrics (Sikorski and Hieter, 1989). We have demonstrated the utility of these vectors by recloning the $S$. cerevisiae $A C E l$ gene.

\section{EXPERIMENTAL AND DISCUSSION}

\section{(a) Plasmid construction}

As described in Fig. 1, we have introduced, in frame, the pBluescript polylinker in the fifth codon of the $U R A 3$ gene. A DNA fragment encompassing this modified $U R A 3$ gene was then introduced into several vectors of the pRS series (kindly provided by Dr. P. Hieter; Sikorski and Hieter, 1989) replacing the lac $Z$ sequences. The resulting plasmids are described in Fig. 2. DNA insertion can be carried out in high-copy $(2 \mu$, ori) or low-copy $(A R S-C E N)$ vectors with Trp or Leu prototrophy selections. All of these plasmids contain numerous restriction sites for cloning including a BamHI site for insertion of DNA fragments generated with Sau3AI and a SmaI site for cloning blunt-ended DNA fragments.

\section{(b) Transformation efficiency}

To test whether the modified URA 3 protein produced by these vectors retains its function, we transformed strain DTY67 (D.J.T., unpublished results) with four plasmids. Table I summarizes the results. Clearly, the modified URA3 gene is functional since it confers uracil prototrophy and 5-FOA sensitivity. Furthermore, we have not observed any decreases in transformation efficiency with these vectors in
TABLE I

Transformation efficiency of the pPSG vectors

\begin{tabular}{llll}
\hline Media $^{\text {a }}$ & \multicolumn{2}{l}{ Number of colonies $/ \mu \mathrm{g}$ of plasmid DNA } \\
\cline { 2 - 4 } & pPSGA & pPSGC & no DNA \\
& $10^{3}$ & 300 & nd \\
SC-Ura-Trp & $10^{3}$ & 300 & $14^{c}$ \\
SC-Trp & 21 & 17 & nd \\
SC-Trp + 5-FOA & & & \\
\cline { 2 - 4 } & pPSGB & pPSGD & no DNA \\
\cline { 2 - 4 } & 600 & 300 & nd \\
SC-Ura-Leu & 600 & 300 & $0^{\circ}$ \\
SC-Leu & 0 & 2 & nd \\
SC-Leu + 5-FOA & & &
\end{tabular}

a The composition of the media is described in Guthrie and Fink (1991).

${ }^{b}$ Cells from strain DTY67 (MATa trp1-1 leu2-3-112 ura3-50 gall his ${ }^{-}$ cupl $1^{\mathrm{s}}$ ace 1-A225; D.J.T., unpublished result) were rendered competent with the lithium acetate method (Ito et al., 1983). They were transformed with $12 \mu \mathrm{g}$ of plasmid DNA and then aliquoted into three parts. Each fraction was then plated on three different $\mathrm{SC}$ media as indicated in the table and incubated at $30^{\circ} \mathrm{C}$. The concentration of $5 . F O A$ was $1 \mathrm{mg} / \mathrm{ml}$. Transformants were counted after three days. nd, not determined. Plasmids are shown in Fig. 2.

- A transformation control was carried out to measure the reversion frequency of the marker. As expected, the trpl-1 allele reverted with a measurable frequency while the leu 2 marker did not

various strains when compared to the plasmids from the pRS series (data not shown). For strain DTY67, this efficiency ranged between 300-1000 transformants per $\mu \mathrm{g}$ of plasmid DNA. The number of false-positive colonies that grew on medium containing 5-FOA after transformation with the uncut plasmids was very low (Table I).

\section{(c) Recloning of $A C E 1$}

The $A C E 1$ gene of $S$. cerevisiae is involved in the induction of metallothionein-encoding gene transcription in response to exogenous $\mathrm{Cu}^{2+}$ ions (Thiele, 1988). Strains with a delction of $A C E 1$ are sensitive to lower $\mathrm{Cu}^{2+}$ concentrations than strains bearing an intact $A C E I$ gene (Butler and Thiele, 1991). This system provided a good opportunity to test our vector system. Table II summarizes the results obtained using one of the pPSG vectors to

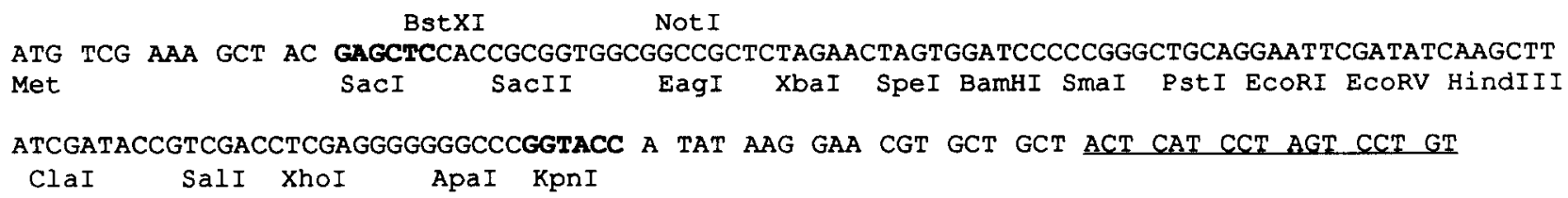

Fig. 1. Sequence of the modificd URA3 coding region. The URA3 gene was modified by conventional techniques (Ausubel et al., 1987) in two steps. (1) Introduction of a $S a c I$ site followed by a $K p n I$ site (bold face) by site-directed mutagenesis after the second nt of the fifth codon of the URA3 coding sequence. (2) Directed cloning of the pBluescript polylinker (Stratagene, La Jolla, CA) between these two restriction sites. The polylinker is thus oriented $5^{\prime}-\mathrm{Sacl}$ to KpnI-3'. 


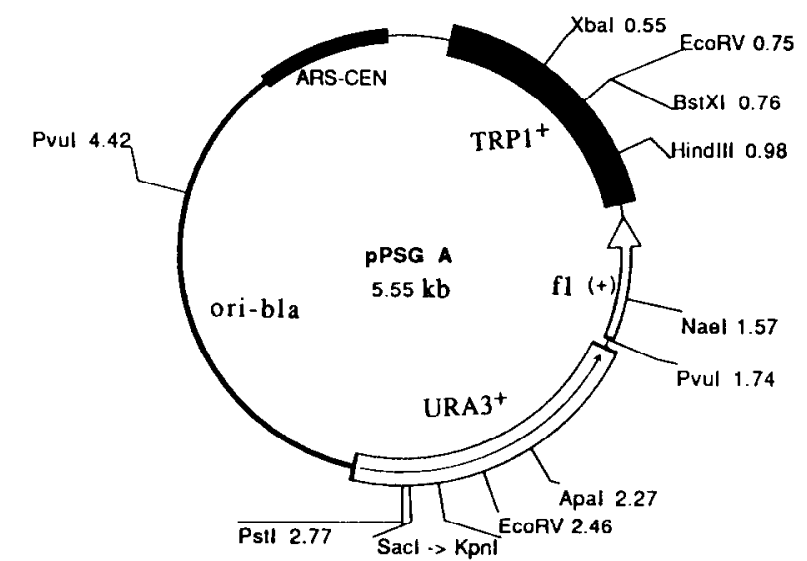

cloning sites: SacI NotI(EagI) BamHI ECORI SalI RpnI SacrI SpeI SmaI ClaI XhoI

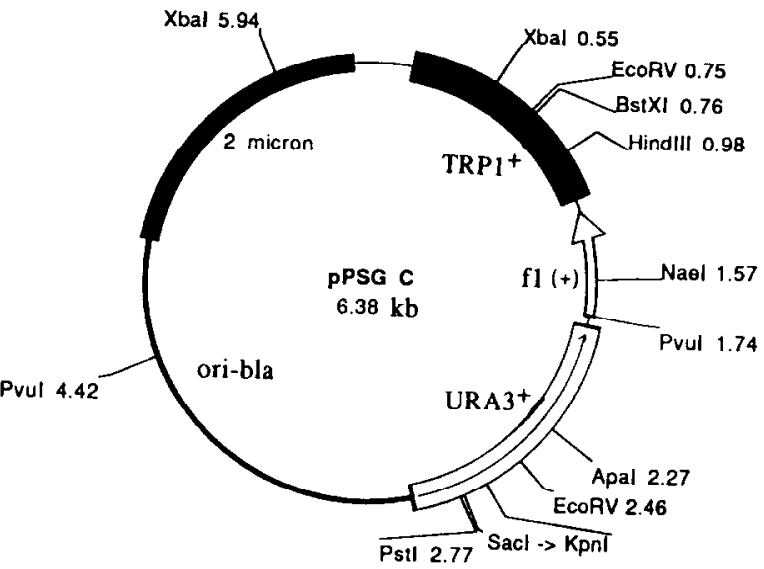

cloning altea: SacI NotI(HagI) BamHI EcoRI SalI XpnI SacII Spar smaI ClaI xhor

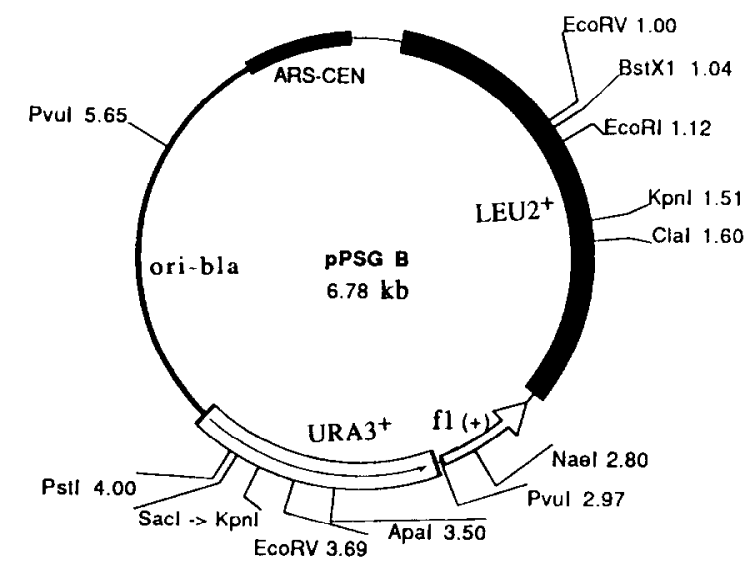

cloning sites: SacI NotI(EagI) SpeI SmaI SalI SacII XbaI BamHI HindIII XhoI

Fig. 2. Structure of the plasmids from the pPSG series. Construction of these plasmids was carried out by using conventional techniques (Ausubel et al., 1987). The 1216-bp HindIII-SmaI fragment encompassing the modified URA3 gene was blunt-ended with PolIk and cloned into the PvuII sites of pRS314, 315,424 and 425 (Sikorski and Hieter, 1989) replacing the lacZ sequences to give pPSG A, B, C and D, respectively. The orientation of the URA3 gene is unchanged with respect to the $\mathrm{fl}$ ori in the four vectors, allowing recovery of the coding strand as ss DNA after superinfection with helper phage. The selection marker, the yeast ori, and the positions (in $\mathrm{kb}$ ) of selected restriction sites are indicated on each plasmid map. The available cloning sites are indicated underneath each plasmid. The polylinker sequence has been verified by direct sequencing of ss DNA obtained from the pPSG vectors with an oligodeoxyribonucleotide complementary to the underlined sequence in Fig. 1.

\section{TABLE II}

Cloning of the $A C E l$ gene $^{\text {a }}$

\begin{tabular}{lllrrrr}
\hline Vector $\mathrm{DNA}^{\mathrm{b}}(\mu \mathrm{g})$ & 3 & 3 & 3 & 3 & 3 & 3 \\
Insert $\mathrm{DNA}^{\mathrm{c}}(\mu \mathrm{g})$ & 0 & 1 & 2 & 3 & 4 & 5 \\
\hline $\begin{array}{l}\text { Number of transformants } \\
\mathrm{Cu}^{2+} \text {-resistant colonies }\end{array}$ & 100 & 1000 & 2500 & 5000 & 5000 & 5000 \\
\hline
\end{tabular}

"All DNA manipulations were carried out according to standard methods (Ausubel et al., 1987).

b Vector DNA was pPSGD cut with BamHI (see Fig. 2).

' Genomic DNA from strain DTY22 (MATa his6 ura3-52 leu2-3, -II2 ACE1 CUP1 ${ }^{\mathrm{R}-3}$; Thiele, 1988) was purified and then digested with Bam HI. Increasing amounts of this digested DNA were ligated with $3 \mu \mathrm{g}$ of BamHI-cut pPSGD.

d The ligation mixtures were used to transform strain DTY59 (MATa his6 leu2 ura3-52 acel-4225 CUP1 ${ }^{\mathrm{R}-3}$; Butler and Thiele, 1991 ) using the lithium acetate method (Ito et al., 1983). Cells were plated on synthetic complete medium lacking leucine and containing 5-FOA at a concentration of $1 \mathrm{mg} / \mathrm{ml}$.

Transformants were counted after two days of incubation at $30^{\circ} \mathrm{C}$.

e Transformant colonies were replica-plated to SC plus $100 \mu \mathrm{M} \mathrm{CuSO}_{4}$. nd, not determined. 
reclone the $A C E I$ gene from genomic DNA. An aceldeletion strain was directly transformed with genomic DNA fragments of an $A C E$ 1 strain ligated into the pPSGD vector. The transformation efficiency was approx. 2500 transformants per $\mu \mathrm{g}$ of uncut plasmid DNA which is typical for this strain transformed with plasmids from the pRS series. The number of transformants per ligation mixture showed an optimum for a given ratio of insert vs. vector DNA, reflecting an optimum for the ligation reaction. Approximately 20000 independent transformants were obtained with the DNA from the ligation mixture. The average size of the inserts was estimated to bc $4^{6}=4096 \mathrm{bp}$. Given the yeast genome size $\left(14 \times 10^{6} \mathrm{bp}\right)$, this bank thus represented five yeast genome equivalents. Transformants were then replica-plated onto SC medium containing $100 \mu \mathrm{M} \mathrm{CuSO}_{4}$. Four $\mathrm{Cu}^{2+}$-resistant isolates were recovered after one day of growth at $30^{\circ} \mathrm{C}$, consistent with the number expected based upon the estimated genome equivalents of the library. Confirmation that the four $\mathrm{Cu}^{2+}$-resistant isolates contained plasmids with the expected insert was then determined by restriction mapping after transfer of the plasmids to E. coli or by Southern blotting. Transformants in the control ligation without any genomic DNA probably arose from integration of residual unligated vector DNA as well as vector incorrectly religated.

The complete procedure took fewer than ten days with no intensive work from the DNA isolation up to the recovery of the plasmids in $E$. coli. The critical step in these experiments is the transformation efficiency of the recipient strain. This can easily be overcome by using more plasmid and genomic DNA, and transforming with a range of ligation reactions as performed in the cloning of $A C E 1$. For the recovery of new genes or mutant alleles, standard procedures can be used to construct libraries. Genomic DNA can be cleaved with Sau3AI restriction enzyme, and the larger fragments (4-20 kb) purified and ligated in the $B a m \mathrm{HI}$ site of the pPSG vectors. This favors the likelihood that only large and random genomic DNA fragments are represented.

\section{(d) Conclusions}

(1) We have constructed new shuttle vectors with a URA3-based selection which allow direct screening of recombinant plasmids after transformation in $S$. cerevisiae. These plasmids can be recovered in E. coli and contain several convenient restriction sites for cloning. The bacteriophage F1 origin of replication is present for the isolation of single-stranded DNA and for subsequent sequencing or mutagenesis of the insert DNA.

(2) Recloning of the $A C E 1$ gene verified the utility of these vectors for the direct cloning of genes by complementation in yeast. These vectors can be used for several purposes such as rapid cloning of genes from expression libraries including genomic banks from $S$. cerevisiae or closely related organisms and cDNA banks. The positions of the $X h o I$ and $E c o$ RI sites allow the directed cloning of cDNAs in an orientation appropriate for expression. These new vectors are particularly useful for the cloning of dominant mutant alleles of yeast genes because their use avoids the time-consuming cloning step in $E$. coli. This also allows one to retrieve sequences that may be toxic in $E$. coli. These vectors can also be used for the expression of fusion proteins driven from the $U R A 3$ promoter or for the construction of yeast promoter-URA3 fusions for use in selections for transcriptional regulatory defects.

\section{ACKNOWLEDGEMENTS}

We thank Kathy Tamai for critically reading the manuscript and for her continued interest in this work, D. Engelke for critically reading the manuscript and $P$. Hieter for pRS plasmids. This work was supported by Public Health Service Grant GM41840 from the National Institutes of Health. P.S. was supported in part by a University of Michigan Postdoctoral Fellowship from the Program in Protein Structure and Design.

\section{REFERENCES}

Ausubel, F.M., Brent, R., Kingston, R.E., Moore, D.D., Seidman, J.G., Smith, J.A. and Struhl, K. (Eds.): Current Protocols in Molecular Biology. Wiley Interscience, New York, 1987.

Boeke, J.D., Lacroute, F. and Fink, G.R.: A positive selection for mutants lacking orotidine-5' -phosphate decarboxylase activity in ycast: 5-fluoro-orotic acid resistance. Mol. Gen. Genet. 197 (1984) 345-346.

Butler, G. and Thiele, D.J.: $A C E 2$, an activator of yeast metallothionein expression which is homologous to SWI5. Mol. Cell. Biol. 11 (1991) 476-485.

Guthrie, C. and Fink, G.R.: Guide to yeast genetics and molecular biology. Methods Enzymol. 194 (1991) 12-18.

Ito, H., Fukuda, Y., Murata, K. and Kimura, A.: Transformation of intact cells treated with alkali cation. J. Bacteriol. 153 (1983) 163-168.

Rose, M., Grifasi, P. and Botstein, D.: Structure and function of the yeast URA3 gene: expression in Escherichia coli. Gene 29 (1984) 113-124.

Sikorski, R.S. and Hieter, P.: A system of shuttle vectors and yeast host strains designed for efficient manipulation of DNA in Saccharomyces cerevisiae. Genetics 122 (1989) 19-27.

Thiele, D.J.: ACE1 regulates expression of the Saccharomyces cerevisiae metallothionein gene. Mol. Cell. Biol. 8 (1988) 2745-2752.

Yanisch-Perron, C., Vieira, J. and Messing, J.: Improved M13 phage cloning vectors and host strains: nucleotide sequence of the M13mp18 and pUC19 vectors. Gene 33 (1985) 103-119 